\title{
CRISIS INMOBILIARIA Y DESAHUCIOS HIPOTECARIOS EN ESPAÑA: UNA PERSPECTIVA GEOGRÁFICA ${ }^{1}$
}

\author{
Ricardo Méndez Gutiérrez del Valle \\ Instituto de Economía, Geografía y Demografía CSIC \\ ricardo.mendez@cchs.csic.es \\ Julio Plaza Tabasco \\ Departamento de Geografía y Ordenación del Territorio, Universidad de Castilla-La Mancha \\ Julio.Plaza@uclm.es
}

\section{RESUMEN}

Los desahucios hipotecarios son una de las más importantes y trágicas manifestaciones sociales del impacto de la crisis inmobiliaria iniciada en 2007. Su observación desde un enfoque geográfico y a diferentes escalas descubre su especial intensidad en numerosas áreas turísticas litorales o de montaña y determinadas periferias metropolitanas, allí donde los excesos del proceso urbanizador, y los costes y riesgos asociados fueron mayores, o donde se concentran los grupos sociales más vulnerables a la crisis. El artículo dibuja el mapa de las ejecuciones hipotecarias en España desde el inicio de la crisis económica y propone una interpretación de sus contrastes.

Palabras clave: Desahucios, crisis inmobiliaria, vulnerabilidad territorial, España.

\footnotetext{
ABSTRACT

Mortgage foreclosures are one of the most important and tragic social manifestations of the impact of the housing crisis that began in 2007. Its observation from a different geographic and multiscale focus discovers its special intensity in many coastal or mountain

Fecha de recepción: junio 2014.

Fecha de aceptación: febrero 2015.

1 El texto forma parte del proyecto de investigación financiado por el Plan Nacional de $I+D+i$ (Ministerio de Economía y Competitividad) sobre Efectos socioterritoriales de la crisis económica en las áreas urbanas de España: políticas públicas y estrategias de resiliencia (CS02012-36170). Los autores agradecen las sugerencias recibidas en el proceso de evaluación.
} 
tourist areas and certain metropolitan peripheries, there where the excesses of urbanization process and the associated costs and risks were higher, or where the most vulnerable to the crisis social groups are concentrated. This paper draws the map of foreclosures in Spain since the beginning of the economic crisis and proposes an interpretation of its contrasts.

Key words: foreclosures, housing crisis, territorial vulnerability, Spain.

Hasta entonces el mal -para llamar de alguna manera a aquel conjunto sobrecogedor de circunstancias sólo inopinado en apariencia- se había insinuado poco a poco, por etapas, de un modo sigiloso y a primera vista inocuo, quizá con el deliberado propósito de no alarmar a los vecinos...No obstante, volviendo la mirada atrás y analizando las cosas con un enfoque retrospectivo, parecía obvio que aquella acumulación de indicios no era simple producto de la casualidad sino que llevaba, por así decirlo, su propia dinámica, una dinámica todavía oculta, como ese caudal de agua enterrada que se hincha y agranda antes de aflorar súbita e impetuosamente».

(Juan Goytisolo: Paisajes después de la batalla, 1982)

\section{INTRODUCCIÓN}

En apenas dos décadas el territorio español ha conocido los efectos del mayor proceso de auge y caída de la actividad y el mercado inmobiliario de toda su historia. Desde mediados de la última década del siglo XX la economía española se vio inmersa en una espiral de crecimiento que tuvo en los sectores financiero e inmobiliario su principal fuente de alimentación. La expansión de una burbuja de activos inmobiliarios, acompañada por otra paralela e indisociable de pasivos hipotecarios, estuvo en el origen de un proceso que trajo consigo profundos desequilibrios que acabaron por mostrar la insostenibilidad a medio plazo de ese modelo de crecimiento, provocando una crisis que aquí ha resultado particularmente intensa y prolongada. Son muchos y valiosos los estudios realizados sobre las claves explicativas de ese periodo, sus principales actores, sus múltiples manifestaciones en el territorio o los costes ambientales y sociales derivados como para volver sobre el mismo con la pretensión de hacer alguna aportación sustantiva. Sí parece, en cambio, necesario profundizar en el masivo endeudamiento de familias y empresas que hizo posible ese crecimiento y, a la postre, acabó ahogándolo.

No obstante, aunque la interrelación existente entre las fases expansiva y recesiva de todo ciclo inmobiliario obliga a recordar esos antecedentes, el objetivo central del artículo es analizar los principales impactos derivados de la crisis inmobiliaria iniciada en 2007 y los fuertes contrastes territoriales observables en su intensidad a diferentes escalas. Entre todos ellos, la atención se centra en una de las consecuencias que mayor gravedad y capacidad de movilización social ha demostrado como son los desahucios provocados por el impago de las deudas hipotecarias contraídas, intentando aportar a los estudios ya disponibles una dimensión geográfica explícita apenas presente en la bibliografía publicada hasta el momento. En ese ámbito, las preguntas de investigación que el artículo pretende responder han sido las siguientes: (i) ¿cómo han evolucionado las ejecuciones hipotecarias desde el inicio de la 
crisis económica en los diferentes territorios?; (ii) ¿qué factores pueden explicar su desigual vulnerabilidad frente a esta manifestación del final del ciclo inmobiliario?; (iii) ¿puede identificarse una tipología de áreas según la intensidad y el crecimiento reciente alcanzado por las ejecuciones hipotecarias?

Para ofrecer una panorámica general de los efectos provocados por la crisis inmobiliaria y su distribución provincial se explotó información procedente de diversas fuentes. De la publicada por el Ministerio de Fomento se consultó la Estadística de Vivienda Libre, que se basa en los proyectos de ejecución visados por los Colegios de Arquitectos, la Estadística de Transacciones Inmobiliarias obtenida a partir de los datos remitidos por la Agencia Notarial de Certificación y la Estadística de Precios de Vivienda, elaborada por el Servicio de Estudios y Estadísticas del propio Ministerio. En la web del Instituto Nacional de Estadística se consultó la Estadística de Hipotecas, que ordena la información obtenida en los Registros de la Propiedad, y en la Asociación Hipotecaria Española se tuvo acceso a la Estadística de Actividad Crediticia Hipotecaria Mensual. Por su parte, para el caso de los desahucios, tras una revisión de las diversas fuentes existentes, la base utilizada para el análisis fue la publicada por el Servicio de Estadística Judicial del Consejo General del Poder Judicial sobre ejecuciones hipotecarias y lanzamientos, por ser la única que permite disponer de una serie temporal suficiente para observar el efecto de la crisis económica y una desagregación que alcanza los 431 partidos judiciales, donde se localizan los juzgados de primera instancia e instrucción. Esto hizo posible la elaboración de un mapa de desahucios mucho más preciso que los disponibles hasta el momento, que permite deducir algunas claves interpretativas.

Con objeto de alcanzar los objetivos planteados, el texto dedica sus dos primeros apartados a recordar las herencias derivadas de la trayectoria inmobiliaria española y las consecuencias principales de su crisis, prestando especial atención a los procesos de desahucio y los factores que pueden explicar su desigual presencia en el territorio. A partir de ese doble contexto histórico y teórico, el tercer epígrafe realiza una breve aproximación a conceptos y fuentes necesarios para abordar una investigación sobre esta temática que cierra la primera parte del trabajo realizado. La segunda corresponde al estudio empírico, que en el cuarto epígrafe analiza los contrastes interprovinciales en el impacto de la crisis inmobiliaria, mientras el quinto aborda con mayor extensión el mapa de las ejecuciones hipotecarias a diferentes escalas, identifica las fuertes desigualdades que lo caracterizan, define una tipología de áreas según su intensidad y el crecimiento registrado desde el inicio de la crisis, con una interpretación de sus posibles factores explicativos que debe entenderse como aproximación inicial a una temática necesitada de estudios más pormenorizados. El artículo finaliza con unas breves conclusiones que reflexionan sobre lo analizado pero no plantean propuestas específicas, consciente de que su principal utilidad debería ser ofrecer nuevos argumentos para abordar nuevas acciones que deberán protagonizar las organizaciones ciudadanas y las instituciones políticas responsables.

\section{HERENCIAS DE UNA TRAYECTORIA: DE LA HIPERTROFIA INMOBILIARIA A LA BURBUJA HIPOTECARIA}

En un contexto general de creciente mercantilización del territorio (De Mattos, 2007; Herce, 2013), lo ocurrido en nuestro país con la promoción inmobiliaria no resultó sino uno 
de sus exponentes, aunque de especial importancia por la dimensión económico-laboral alcanzada y por provocar una verdadera metamorfosis urbana. España se convirtió así en uno de los ejemplos internacionales más significativos en cuanto a la expansión registrada por el circuito secundario de acumulación de capital, vinculado de forma directa a la producción del espacio urbano (Harvey, 2007; López y Rodríguez, 2013).

El modelo inmobiliario español resulta indisociable del proceso de financiarización económica y la conformación de un bloque hegemónico financiero-inmobiliario que convirtió el negocio de la ciudad y la consecución de una sociedad de propietarios en su principal fuente de ingresos (García Montalvo y Más, 2000; Fernández Durán, 2006; Burriel, 2008; Naredo, 2009 y 2010; López y Rodríguez, 2010; Fernández Tabales y Cruz, 2013; Vinuesa, 2013). Algunas simples cifras dan cuenta de la intensidad que alcanzó ese proceso:

- Si el número de viviendas iniciadas en 1996 fue de 282,4 miles, esa cifra se duplicó con creces en 2003 (636,3 miles), para alcanzar los 863,8 miles en 2006, iniciar un ligero descenso al año siguiente $(651,4$ miles) y sumar un total de 7,12 millones en el trascurso de ese periodo.

- Por su parte, si en 1996 fueron 253,4 miles las viviendas finalizadas, esa cifra también mantuvo un crecimiento constante hasta alcanzar su máximo en 2007 (641,4 miles), sumando igualmente en esos doce años una cifra final de cinco millones según los certificados de fin de obra expedidos por los Colegios de Aparejadores.

- Como reflejo de las peculiaridades inherentes al mercado inmobiliario, ese fuerte incremento de la oferta se acompañó por otro no menor de los precios de la vivienda libre que, de un promedio de 694,4 euros $/ \mathrm{m}^{2}$ en 1996, duplicó ese valor en 2003 (1.380,3 euros $/ \mathrm{m}^{2}$ ) y lo triplicó (2.085,5 euros $/ \mathrm{m}^{2}$ ) en 2007. Pese al aumento de población registrado en esos años por inmigración, se ha estimado que tan sólo un $30 \%$ de las viviendas construidas se relacionó con la formación de nuevos hogares (Alguacil Denche et al., 2013), lo que limita el efecto ejercido por el factor demanda en esa evolución de los precios.

Las elevadas tasas de crecimiento registradas por todos los indicadores mencionados resultan coherentes con la conversión de la vivienda no sólo en un bien de consumo cada vez más sometido a la lógica del mercado ante la decreciente participación del Estado en su producción, sino ante todo en un bien de inversión. Al tratarse de un activo aparentemente seguro y de alta rentabilidad a corto plazo, atrajo un volumen creciente de capital destinado a nutrir todas las etapas del proceso, desde la adquisición del suelo y la edificación hasta la compra de los inmuebles por las familias. El abandono de su función social hizo posible la aparente paradoja de asistir a una producción desaforada de viviendas basada en una lógica ajena a las necesidades reales de alojamiento de la población, lo que provocó la exclusión de amplios sectores sociales -en especial jóvenes que pretendían acceder a su primera vivienda y grupos de bajos ingresos-, dentro de un mercado con excedentes no vendidos cada vez más abundantes.

Pero es indudable que, para poder aumentar su tamaño durante más de una década, la burbuja inmobiliaria tuvo que contar con un importante apoyo público, tanto directo como indirecto, lo que ha permitido interpretaciones del proceso que incorporan un componente 
político explícito (Romero, 2010; García, 2010; Romero, Jiménez y Villoria, 2012). En primer lugar, la Ley 6/1998 sobre régimen del suelo y valoraciones liberalizó ese mercado y convirtió buena parte del territorio en un solar potencialmente urbanizable de no existir una figura de protección explícita, al tiempo que aceptaba el protagonismo de los agentes urbanizadores privados en detrimento de una ordenación del territorio más efectiva en el establecimiento de controles (Burriel, 2011). Por el contrario, en bastantes casos las directrices de ordenación de ámbito autonómico -cuando existieron- y el planeamiento municipal multiplicaron el suelo urbanizable y favorecieron grandes proyectos urbanizadores bajo el común argumento de la creación de empleo y riqueza. La importancia de esta actividad inmobiliaria en la financiación de las haciendas locales y, demasiado a menudo, la connivencia de los responsables públicos con determinados intereses privados acabaron por justificar ese planeamiento expansivo de nuevos desarrollos accesibles gracias a la inversión pública en infraestructuras de comunicación, del que pocos responsables públicos se atrevieron a quedar al margen.

Al mismo tiempo, el progresivo abandono de la producción por el sector público de viviendas con precio tasado se produjo en beneficio de aquellas otras de precio libre y promoción privada, dueñas absolutas del mercado. Pero si ese gasto público en la producción de vivienda sufrió una evidente contracción, el apoyo indirecto a la compra de vivienda de promoción privada mediante incentivos fiscales resultó tres veces superior para el conjunto del periodo considerado. Iniciados ya en 1978 y ampliados más tarde para acoger incluso a la compra de la vivienda no habitual -frente a su ausencia en el caso del alquiler- supusieron una inyección de recursos públicos que sirvió de combustible para alimentar la máquina del crecimiento urbano e incentivar el endeudamiento de un número creciente de ciudadanos, que solicitaban a las entidades financieras créditos parcialmente subvencionados mediante la correspondiente desgravación en su declaración del IRPF.

El resultado fue que en 2007 nada menos que un $87 \%$ de la población accedía a la vivienda mediante compra, por tan sólo un $13 \%$ a través del alquiler, lo que suponía un desajuste de casi treinta puntos respecto al promedio de la Unión Europea. Esa situación sólo fue posible mediante el crecimiento paralelo de una burbuja crediticia que respondió a esa confluencia de estrategias privadas y públicas, de la que conviene recordar ahora algunos de sus rasgos y dimensiones más característicos como base para interpretar lo ocurrido al agotarse ese ciclo inmobiliario.

La oportunidad que supuso la incorporación a la Unión Europea y más tarde al euro favoreció un marco de estabilidad monetaria y bajos tipos de interés que sirvió como escenario idóneo para desarrollar el proceso. Al mismo tiempo, todas las entidades financieras aplicaron una estrategia deliberada para ampliar el mercado hipotecario recurriendo a su endeudamiento con otros bancos y fondos de inversión internacionales mientras competían para convertir en demanda solvente a sectores sociales con condiciones de precariedad laboral y niveles salariales que aumentaban el riesgo de impago. En ese sentido, «que los créditos hipotecarios pasasen a ser el negocio principal para las entidades financieras derivó en un abandono de buenas prácticas hipotecarias» (Trabada, 2012: 177), como que el préstamo no superase el $80 \%$ del valor de tasación, la cuota a pagar no se elevase más allá del $40 \%$ de los ingresos familiares, o el plazo de amortización no fuese mayor de 30 años.

El efecto combinado del constante aumento en la firma de hipotecas y la espiral especulativa de los precios provocó un acelerado crecimiento en el importe de las hipotecas 
concedidas anualmente. Según la Estadística Hipotecaria del INE, las 412.982 hipotecas constituidas para la compra de vivienda en 1996 aumentaron hasta superar ampliamente el millón anual entre 2005-07 y sumar un total de 9.367.493 hipotecas en el conjunto de esos doce años. El importe total concedido, de 19.566,2 millones de euros al inicio del ciclo, llegó a multiplicarse casi por diez en los años finales del mismo, con un máximo de $188.339,1$ millones en 2006. Por su parte, según datos de la Asociación Hipotecaria Española (AHE), el saldo vivo en balance del crédito hipotecario a los hogares destinado a la compra de vivienda era de 81.584 millones de euros en 1996, pero aumentó con rapidez al concederse nuevos préstamos a un ritmo muy superior al de amortización de los preexistentes hasta alcanzar su máximo en el año 2010 (632.437 millones).

De este modo, el efecto riqueza provocado por la revalorización de los activos inmobiliarios tuvo su contrapunto en un sobreendeudamiento para su adquisición, que en el caso de las familias supuso pasar de una cifra equivalente al $46 \%$ de la renta anual bruta disponible al inicio del periodo hasta alcanzar el 134\% a su finalización (Sánchez Martínez, 2008; Rodríguez López, 2009). La progresiva saturación del mercado hipotecario, ya visible en 2007, y la profunda crisis financiera internacional iniciada al año siguiente pusieron en evidencia los graves efectos derivados de esa elevada exposición al riesgo, que alcanzó cotas extremas en algunos territorios que son también los afectados ahora de forma más grave por los costes económicos y sociales derivados.

\section{PAISAJES DESPUÉS DE LA BATALLA: IMPACTOS DE LA CRISIS Y DESAHUCIOS HIPOTE- CARIOS. ¿UNA LÓGICA ESPACIAL?}

Tras un largo periodo de crecimiento que transformó tanto su morfología como sus restantes características, el territorio español se enfrenta en los últimos años al final de ese ciclo inmobiliario que algunos creyeron inagotable pero que, una vez más, ha puesto en evidencia los límites del sistema y la periodicidad de sus crisis (Daher, 2013). La creciente dificultad para continuar ampliando la demanda solvente, capaz de acceder a la compra de una vivienda ampliamente sobrevalorada, junto al aumento del riesgo hipotecario y el repunte de la morosidad que acompañó el aumento de los tipos de interés desde 2006, pusieron freno al proceso a partir del año siguiente. La crisis de las hipotecas subprime en Estados Unidos, que desde septiembre de 2008 provocó el hundimiento y rescate de numerosas entidades financieras, víctimas de los excesos asumidos con la multiplicación de préstamos y una titulización de la deuda que pretendió dispersar el riesgo hipotecario para convertirlo en sistémico, oficializó la quiebra del modelo (Krugman, 2009; Bellamy Foster y Magdoff, 2009).

Como alumno aventajado de ese crecimiento inmobiliario-financiero, el caso español se convirtió también en uno de los mejores exponentes de su hundimiento y de nuevo el mercado hipotecario resultó un buen reflejo de la contracción producida. Si las fuertes restricciones crediticias y el endurecimiento en las condiciones de acceso a los préstamos hipotecarios, junto al creciente desempleo, precarización y deterioro en las condiciones de vida de una parte de la población provocaron la brusca retracción de la demanda inmobiliaria, otro tanto ocurrió con la oferta. La paralización de su negocio y la imposibilidad de devolución de parte de unos préstamos cifrados en 319.294 millones de euros en 2008 se tradujeron en la quiebra 
en cascada de empresas inmobiliarias, constructoras y numerosas industrias o servicios auxiliares, con la consiguiente destrucción de empleo y el trasvase de una parte de sus activos (suelo, viviendas, inmuebles empresariales) a las entidades acreedoras.

No es objetivo de estas páginas incidir en algunos daños colaterales del proceso, como la profunda reestructuración del sistema financiero español en beneficio de la gran Banca y la desaparición de las Cajas de Ahorro, o la creación en 2012 de la Sociedad de Gestión de Activos Procedentes de la Reestructuración Bancaria (SAREB), ese banco malo encargado de limpiar de activos tóxicos el balance de los restantes. Tampoco realizar un análisis pormenorizado de las herencias que deja en forma de stock de viviendas y suelo, o de inadecuación del planeamiento urbanístico, como el realizado por Burriel (2014). Pero sí lo es, en cambio, sintetizar algunos efectos de este proceso sobre el territorio y, en especial, sobre las áreas urbanas, que junto con las litorales fueron las más afectadas, por su estrecha relación con lo aquí investigado. Esas múltiples manifestaciones, intangibles unas y visibles otras, pueden quedar englobadas bajo la metáfora de los paisajes después de la batalla, en alusión a la novela de Goytisolo que tiene como trasfondo la compleja y contradictoria transformación de un espacio urbano.

En el plano estrictamente económico, la traslación de estas nuevas condiciones a la paralización registrada por la actividad y el mercado inmobiliario fue directa, con caídas espectaculares en la construcción, venta y precio de las viviendas, aunque también con intensidades y ritmos bastante heterogéneos según territorios, tal como habrá ocasión de precisar más adelante. Al mismo tiempo, resulta innegable la cristalización de unos paisajes que son herederos directos de la burbuja inmobiliaria y materializan visualmente su crisis de diversas formas, desde la presencia de grandes áreas urbanizadas vacías, sin otra expectativa aparente que la incierta e indeseable reproducción de un nuevo ciclo similar al anterior, a los equipamientos públicos y urbanizaciones periféricas sin terminar, paralizados por la quiebra de quienes los promovían o el traslado de los inversores a nuevos espacios emergentes donde repetir sus estrategias. También en las urbanizaciones ya terminadas y ocupadas por muy escasos residentes, varados en medio de espacios abandonados y a menudo mal conectados que no justifican la instalación de servicios de proximidad para atender sus demandas, pese a lo cual parecen convertirse en nuevo objeto de deseo para fondos de inversión interesados en su bajo precio.

Pero otra consecuencia del proceso ha sido la multiplicación de los desahucios, reflejo visible del proceso de acumulación por desposesión denunciado por Harvey (2004), al tiempo que origen de nuevas formas de exclusión residencial y detonante de una creciente movilización social que, junto a fenómenos de resistencia y denuncia, ha llegado a traducirse en algo tan poco usual en nuestro sistema político como una iniciativa legislativa popular. Si bien el fenómeno no es nuevo, y Capel (2013: 364) recuerda la presencia ya documentada en el siglo XIX e inicios del XX de numerosos «desahucios de inquilinos que ocupaban pisos en alquiler y que no podían pagarlos», la dimensión alcanzada en estos años y su especial vinculación con los impagos hipotecarios le han dotado de una gravedad desconocida hasta el presente, pues «la privación de la vivienda puede situar a una familia en las puertas de la vulnerabilidad y a un paso de la exclusión social» (Arredondo y Palma, 2013: 118).

Se trata de un proceso complejo, que inicia su andadura con el impago del préstamo hipotecario y la interposición por vía judicial de una demanda por parte del acreedor -casi siem- 
pre una entidad financiera- para reclamar los pagos pendientes, presentando una ejecución hipotecaria para su tramitación en los Juzgados de Primera Instancia e Instrucción. Si se resuelve de forma favorable al demandante, el proceso acabará conduciendo en sucesivos pasos hasta la subasta del inmueble y el lanzamiento forzoso de quienes residían en él, en caso de estar ocupado. La intensidad alcanzada desde el inicio de la actual crisis no sólo lo ha convertido en motivo de alarma y movilización social, sino que también justifica la aparición de diversos estudios recientes que, pese a las limitaciones en la información estadística disponible y la dificultad para aplicar técnicas de análisis cualitativas a un colectivo mal conocido y disperso, son la base de partida para una investigación como la aquí presentada.

Están, en primer lugar, los promovidos desde colectivos particularmente activos en la defensa de los derechos de quienes se ven afectados por estos procesos, la contestación y la búsqueda de respuestas políticas a la situación planteada como son la Plataforma de Afectados por la Hipoteca y el Observatorio DESC (Colau, 2012; Colau y Alemany, 2012 y 2013). Están también los que, desde el ámbito académico, han abordado un análisis de los datos disponibles sobre su evolución en el contexto europeo y como indicador de la actual crisis inmobiliaria, considerando también su reparto entre Comunidades Autónomas (Etxezarreta et al., 2012 y 2013; Valenzuela, 2013). Pueden mencionarse finalmente los que aportan una aproximación a las características de los afectados, así como a las múltiples consecuencias provocadas en su situación personal y familiar, mediante la realización de encuestas o entrevistas con un ámbito territorial y temporal diverso (Valiño, 2013; Arredondo y Palma, 2013). Pese a lo limitado de la investigación realizada hasta el momento en esta última línea, la convergencia en algunas de sus conclusiones con estudios publicados en otro país con gran volumen de desahucios como Estados Unidos (Kingsley, Smith y Price, 2009; Axel-Lute, 2009; Been y Gould, 2012) aporta cierta capacidad de generalización a esos resultados.

Entre sus muchas conclusiones de interés, la elevada presencia entre los afectados por procesos de desahucio de personas que sí residían en la vivienda objeto del proceso, que contrajeron la deuda hipotecaria en pleno boom inmobiliario y mantienen, por tanto, sin pagar una elevada proporción del préstamo, la caída en el desempleo como principal factor del impago, o la presencia habitual de personas dependientes en el hogar son algunas bastante repetidas. El impacto que la amenaza de expulsión provoca en forma de ansiedad y problemas de salud, cambios en la situación familiar, absentismo escolar en el caso de menores o reducción general de otro tipo de gastos para intentar afrontar el pago son también consecuencias habituales que conducen a situaciones de exclusión social.

Es, pues, indudable que en el fuerte incremento de los procesos de desahucio por impago hipotecario convergen factores estructurales, derivados de la crisis económica y el devastador efecto de las políticas neoliberales de austeridad fiscal, con características personales o familiares que reducen la capacidad de resistencia ante las dificultades planteadas. Pero si a esa mirada dicotómica se incorpora una perspectiva territorial, se constata que esos desalojos no se distribuyen de forma aleatoria y que, una vez iniciado el proceso, sus impactos negativos no se limitan al interior del hogar, sino que se difunden con mayor intensidad y de formas diversas en el entorno próximo. Si las crisis capitalistas siempre provocan nuevas manifestaciones de los procesos de desarrollo geográfico desigual (Hadjimichalis, 2011), 
comprender mejor las causas que subyacen al mapa de los desahucios, así como su influencia sobre la aparición o el reforzamiento de áreas-problema, puede justificar una breve reflexión al respecto pues, como afirman Kaplan y Sommers (2009: 102), «sus causas y efectos son profundamente geográficos».

Todos los territorios se han visto afectados por una intensificación del fenómeno como resultado de la crisis económica, acentuada por las medidas de austeridad fiscal impuestas desde 2010. Pero las diferencias observables en cuanto a densidad y tasa de crecimiento del número de desahucios, tanto entre áreas urbanas como en el interior de las mismas, plantean el reto de identificar sus posibles claves. Una hipótesis significativa es la que propone que «el mapa de la crisis es casi exactamente el negativo del mapa de la burbuja» (Burriel, 2014: 106). Complementaria a esta es la que aquí se propone y que vincula esa diversa intensidad con el desigual grado de vulnerabilidad que presenta cada área (Figura 1).

Puede considerarse vulnerable a aquel territorio (región, comarca, ciudad, barrio) que, ante condiciones externas adversas, muestra una alta probabilidad de verse especialmente dañado. Tal como planteó el Departamento de Asuntos Económicos y Sociales de Naciones Unidas hace ya más de una década, la vulnerabilidad supone «un estado de elevada exposición a determinados riesgos e incertidumbres, combinado con una capacidad disminuida para protegerse o defenderse de ellos» (Naciones Unidas, 2003: 8). Exposición y sensibilidad o fragilidad son, pues, conceptos asociados a los de vulnerabilidad territorial o urbana y la literatura científica de los últimos años, con matices diversos, así lo ha planteado (Hernández Aja, 2007; Day et al., 2009; Seeliger y Turok, 2013; Alguacil et al., 2014; Ranzi, Brandsen y Sabatinelli, 2014), incluida aquella que los vincula al desigual impacto urbano de la actual crisis (Méndez, 2013a, 2013b; Méndez y Prada, 2014).

Figura 1

CONTRASTES TERRITORIALES EN LOS PROCESOS DE DESAHUCIO:

UNA INTERPRETACIÓN.

\section{Factores externos}

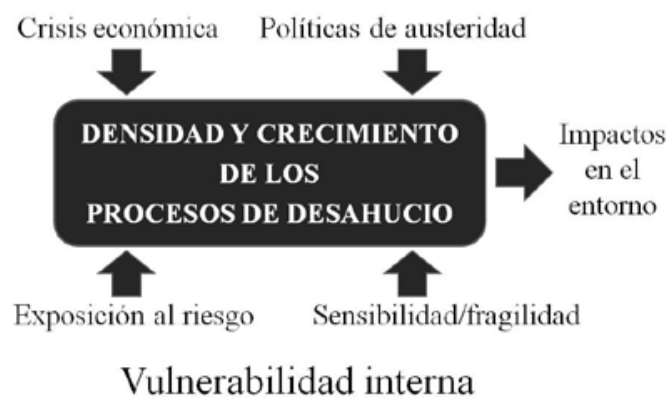

Fuente: elaboración propia.

La conjunción de factores externos e internos puede dar cuenta, por tanto, del heterogéneo reparto que muestran tanto ejecuciones hipotecarias como lanzamientos, pero en relación a las características territoriales que los favorecen pueden considerarse a modo 
de hipótesis dos tipos de razones que se superponen. Por un lado, el grado de sensibilidad podrá relacionarse con la mayor o menor presencia en el área de aquellos grupos sociales más frágiles, ya sea debido a su bajo nivel de ingresos y cualificación, disponer de un empleo precario o estar en paro, integrar una familia monoparental, etc. Pero, además, la exposición será también mayor en aquellas áreas que fueron exponente del modelo de crecimiento basado en el inmobiliario, especializadas en actividades intensamente afectadas por la crisis como la construcción y las industrias auxiliares, que padecen un elevado nivel de endeudamiento hipotecario.

La presencia de un elevado número de desahucios en un área también difunde efectos negativos sobre su entorno, que moderan su gradiente con la distancia. Los estudios disponibles para el caso estadounidense fijaron su atención, sobre todo, en la desvalorización provocada en el precio de las viviendas próximas (Immergluck y Smith, 2006; Harding, Rosenblatt y Yao, 2008). Pero, en términos más amplios, puede hablarse de la puesta en marcha de un círculo vicioso que comienza con una situación de fragilidad social reflejada en el abandono forzado de viviendas y el traslado de sus residentes (a otro barrio, a otra ciudad...), el deterioro y la devaluación del entorno (imagen externa, conflictividad por resistencia a desahucios, ocupación de viviendas vacías...), lo que acabará aumentando la vulnerabilidad del área.

Resulta imposible responder aquí con solvencia a todas estas cuestiones, que deben entenderse más como un conjunto de interrogantes sin apenas respuesta hasta el momento. Las páginas que siguen intentarán, no obstante, una aproximación a aquellos aspectos que resultan accesibles con la información estadística de que disponemos -que no permite estudios intraurbanos, pese a su evidente importancia-, a expensas de que nuevas investigaciones más pormenorizadas doten de mayor densidad a sus conclusiones.

\section{ALGUNAS CUESTIONES METODOLÓGICAS}

El creciente problema social y político generado por los desahucios ha conllevado un paralelo aumento en la demanda de información sobre los mismos y una diversificación de las fuentes disponibles a partir de 2012. Esta situación exige identificar con precisión las aquí utilizadas, sus razones, características y limitaciones para el objetivo de territorializar estos procesos.

Tradicionalmente y hasta la actualidad la principal fuente de información es el Consejo General del Poder Judicial (CGPJ) a través de la Estadística Judicial, que recoge con periodicidad trimestral las actuaciones de los órganos judiciales. El indicador más utilizado es el de ejecuciones hipotecarias, procedimiento que se presenta en los juzgados de primera instancia, o de primera instancia e instrucción, que permite al acreedor exigir el pago de la deuda garantizada por la hipoteca y para el que existen datos sobre las presentadas o iniciadas, resueltas y en tramitación. No obstante, su principal deficiencia radica en que no distingue el bien hipotecado, lo que supone incluir tanto viviendas (principales o secundarias, ocupadas o vacías) como otro tipo de inmuebles (locales comerciales o industriales, oficinas, garajes...). Más próxima a la noción de desahucio o desalojo es la estadística sobre lanzamientos solicitados a los servicios comunes de actos de comunicación y ejecución, así como de aquellos que tuvieron un cumplimiento positivo y se llevaron a 
efecto. En este caso, a la no distinción sobre el tipo de bien se añade la posibilidad de que el lanzamiento tenga su origen en un impago hipotecario o en el incumplimiento de un contrato de arrendamiento, diferencia no recogida en esa estadística.

Esta ha sido hasta hace poco la única información disponible y sobre ella se han realizado la práctica totalidad de análisis y valoraciones sobre los desahucios en España, pero sus notorias insuficiencias han promovido la aparición de nuevos datos que ahora deben conciliarse con los anteriores. Por una parte, el propio CGPJ inició en 2012 una serie sobre los lanzamientos acordados y practicados por los juzgados de primera instancia e instrucción que considera bastante más fiable que la anterior (porque no existen servicios comunes en todos los partidos judiciales) y que eleva de forma sustancial su cifra, diferenciando los derivados de una ejecución hipotecaria del resto. Por otra, el Colegio de Registradores de la Propiedad publicó en 2012 un informe sobre impagos hipotecarios de vivienda en ese año (Registradores de España, 2012), que recogió el volumen de ejecuciones hipotecarias iniciadas, el de adjudicaciones de vivienda por ejecución de hipoteca y el de daciones en pago, confirmando por ejemplo que el $74,8 \%$ de las ejecuciones correspondieron a viviendas principales. En 2013 el Banco de España comenzó a elaborar una nueva estadística sobre procesos de ejecución hipotecaria de viviendas a partir de una encuesta dirigida a entidades financieras que concentran el $85 \%$ del crédito hipotecario vivo a hogares y que aporta datos sobre las entregas de viviendas realizadas y sobre el hecho de estar o no ocupadas como principal novedad (Banco de España, 2013). Por último, el INE ha iniciado una Encuesta sobre Ejecuciones Hipotecarias en colaboración con el Colegio de Registradores de la Propiedad que ha presentado sus primeros datos en 2014.

No es nuestro objetivo hacer una comparación entre fuentes ya realizada en otras publicaciones (CGPJ, 2013; Valenzuela, 2013) ni entrar en el debate sobre la verdadera dimensión de los desahucios. Por el contrario, el hecho de que los datos del CGPJ sean los únicos que permiten disponer de una serie temporal y una desagregación territorial para poder valorar el desigual impacto temporal y espacial de la crisis justifican que sea la fuente utilizada. Las especiales limitaciones de la información sobre lanzamientos ha orientado nuestra investigación a las ejecuciones hipotecarias, que suponen la primera etapa en los procesos de desahucio, pues no todas terminan en lanzamiento, y aportan por tanto una visión parcial que por el momento no es posible superar.

Respecto a las unidades territoriales de análisis, se comienza ofreciendo una panorámica general a escala provincial para luego desagregar la información entre los 431 partidos judiciales existentes en España. Se trata de la unidad territorial básica para la administración de justicia y que está en vigor de manera continua desde 1834, aunque ha conocido numerosos cambios en su número y delimitación. Está integrada por varios municipios limítrofes de una misma provincia, salvo en 27 ciudades en donde se identifican con el propio municipio, y en la cabeza del partido se localizan los juzgados de primera instancia donde se tramitan las ejecuciones hipotecarias.

Pese a tratarse de una delimitación inusual fuera de este ámbito, la búsqueda de accesibilidad por parte del ciudadano favoreció que su tamaño fuese bastante limitado, adecuándose al volumen de población y los medios de comunicación existentes. El resultado es que en la mayoría de casos $(89,9 \%)$ la distancia media de los municipios a la cabeza del partido es inferior a los 20 kilómetros, lo que permite ofrecer un mosaico territorial complejo, que se 
verá empobrecido de concretarse la reforma actual propuesta para reducir a 199 su número. En cualquier caso, la imposibilidad de acceder a información para unidades inferiores vuelve a poner en evidencia la dificultad actual para realizar estudios a escala urbana, que es donde se concentran buena parte de estos procesos.

\section{TRAS EL FINAL DEL CICLO: CONTRASTES EN LA EVOLUCIÓN RECIENTE DE ALGUNOS INDICADORES INMOBILIARIOS EN ESPAÑA.}

La hipertrofia del sector inmobiliario español durante la fase expansiva del ciclo ha tenido su contrapunto en la intensidad del declive registrado en estos últimos años, tanto en la construcción de viviendas como en su venta o en el precio alcanzado. Los datos del periodo 20062013 muestran una tendencia similar, cualquiera que sea el indicador considerado (Tabla 1).

Tabla 1

EVOLUCIÓN DE LA PRODUCCIÓN Y EL MERCADO INMOBILIARIO EN ESPAÑA, 2006-2013

\begin{tabular}{|c|c|c|c|c|c|c|c|}
\hline Años & $\begin{array}{l}\text { Viviendas } \\
\text { iniciadas } \\
\text { (miles) }\end{array}$ & $\begin{array}{l}\text { Viviendas } \\
\text { acabadas } \\
\text { (miles) }\end{array}$ & $\begin{array}{c}\text { Compraventa } \\
\text { de viviendas } \\
\text { (miles) }\end{array}$ & $\begin{array}{l}\text { Precio medio } \\
\text { vivienda libre } \\
\quad(€ / \mathrm{m} 2)\end{array}$ & $\begin{array}{c}\text { Hipotecas } \\
\text { constituidas } \\
\text { sobre } \\
\text { vivienda }\end{array}$ & $\begin{array}{l}\text { Importe de } \\
\text { hipotecas } \\
\text { concedidas } \\
\text { (millones } \\
€ \text { ) }\end{array}$ & $\begin{array}{l}\text { Saldo crédito } \\
\text { a hogares } \\
\text { para vivienda } \\
\text { (millones } € \text { ) }\end{array}$ \\
\hline 2006 & 863,8 & 585,6 & 955,2 & $1.990,5$ & 1.342 .171 & $188.339,1$ & 519.225 \\
\hline 2007 & 651,4 & 641,4 & 836,9 & $2.085,5$ & 1.238 .890 & $184.427,2$ & 590.580 \\
\hline 2008 & 264,8 & 615,1 & 564,5 & $2.018,5$ & 836.419 & $116.809,9$ & 621.305 \\
\hline 2009 & 111,1 & 387,1 & 463,7 & $1.892,3$ & 650.889 & $76.677,1$ & 624.734 \\
\hline 2010 & 91,7 & 257,4 & 491,3 & $1.825,5$ & 607.535 & $71.041,2$ & 632.437 \\
\hline 2011 & 78,3 & 167,9 & 349,1 & $1.701,8$ & 408.461 & $45.715,9$ & 626.450 \\
\hline 2012 & 44,2 & 120,2 & 363,6 & $1.531,2$ & 273.873 & $28.328,9$ & 605.064 \\
\hline 2013 & 33,9 & 64,6 & 300,3 & $1.466,9$ & 197.641 & $19.732,0$ & 580.764 \\
\hline $\begin{array}{c}\text { Evolución } \\
\text { 2006-13 (\%) }\end{array}$ & $-96,08$ & $-88,97$ & $-68,56$ & $-26,30$ & $-85,27$ & $-89,52$ & 11,85 \\
\hline
\end{tabular}

Fuente: Ministerio de Fomento, INE y Asociación Hipotecaria Española.

De este modo, las 585,6 miles de viviendas acabadas el primero de esos años se redujeron hasta las 64,6 miles de 2013, lo que equivale a un retroceso del -88,97\%. Mayor resultó aún la paralización de la actividad constructiva en el caso de las viviendas iniciadas, que de 863,8 miles descendieron a apenas 33,9 mil (-96,08\%) ante la falta de crédito y expectativas de demanda a medida que aumentó el stock no vendido. La compraventa de vivienda sufrió una retracción paralela, cifrada en un -68,56\% (de 955,2 a 300,3 miles) y, pese a la resistencia mostrada en los primeros años de la crisis a la espera de una recuperación que no llegó, la depreciación sufrida por la vivienda libre acabó generalizándose y supuso un valor medio del -26,30\% en el conjunto de esos años (de 1.990,5 a 1.466,9 euros por metro cuadrado).

Esta tendencia tan marcada resultó, de nuevo, estrechamente correlacionada con la progresiva involución de un mercado hipotecario que había estado en los cimientos del extraor- 
dinario dinamismo inmobiliario anterior. Las 1.342,2 miles de hipotecas concedidas en 2006 se quedaron en 197,6 miles en $2013(-85,27 \%)$ y aún resultó mayor la disminución del importe concedido $(-89,52 \%)$. De modo mucho más lento, el saldo vivo del crédito hipotecario de las familias para la compra de vivienda sólo comenzó a reducirse por primera vez en las últimas dos décadas a partir de 2011, hasta los 580.764 millones de euros en 2013.

Del efecto provocado por el final de la fase expansiva del ciclo inmobiliario no se ha librado ningún territorio, pero la simple observación de lo ocurrido a escala provincial confirma que existen diferencias apreciables en esa evolución y que su distribución no resulta aleatoria. Por el contrario, la intensidad de la recesión padecida por el sector ha sido en cierta medida proporcional a los excesos cometidos con anterioridad. El contraste entre lo ocurrido en el sexenio 2007-2013 con respecto a tres indicadores tan significativos como el número de viviendas libres terminadas anualmente, su precio medio y el volumen de transacciones realizadas supone una primera aproximación a esas regularidades espaciales.

En el caso de las viviendas terminadas cada año (Figura 2a), se ha registrado la práctica paralización de la actividad constructiva en buena parte del territorio español, con especial intensidad en todo el litoral mediterráneo, los dos archipiélagos y algunas provincias interiores como Toledo o Guadalajara, en la periferia de Madrid, o algunas pirenaicas. Esa situación alcanza niveles en torno al 98\% en Castellón (máximo de -98,56\%), Tarragona, Málaga, Murcia, Las Palmas o Lleida, mientras la caída se mantuvo por debajo del $60 \%$ en Guipúzcoa (mínimo de $-53,23 \%$ ) y Vizcaya, además de Melilla.

La depreciación de esos activos inmobiliarios también ha mostrado diferencias nada casuales en su distribución, incluso más acusadas (Figura 2b). La reducción del precio medio de la vivienda libre fue de nuevo particularmente notable en el Eje Mediterráneo y Canarias, pero también llegó a superar el 38\% de su valor inicial en las provincias hacia las que desbordó el crecimiento metropolitano madrileño como Guadalajara (máximo de -40,52\%) y Toledo, además de Zaragoza. Apenas superó, en cambio, la cuarta parte de esa depreciación en los casos de Guipúzcoa (mínimo de -8,34\%), Cáceres y Ourense, además de las dos ciudades autónomas.

Finalmente, la compraventa de viviendas es el indicador que se contrajo de una forma geográficamente más homogénea y donde los factores locales dificultan en mayor medida deducir tendencias regionales bien definidas (Figura 2c). No obstante, esa retracción superó en casi diez puntos el promedio español en casos como los de Asturias (máximo de -76,88\%), Cantabria, León, Jaén o Cuenca, que no habían estado entre las que contaron con un mercado inmobiliario más dinámico en el periodo precedente. En el extremo opuesto, la caída de ventas no alcanzó el $50 \%$ en Madrid $(-49,82 \%)$ y en valores próximos se situaron provincias mediterráneas como Girona, Barcelona, Alicante o Málaga, junto a Santa Cruz de Tenerife, Guipúzcoa o Lugo. La recuperación de la inversión extranjera en los dos últimos años -tanto de particulares en las áreas turísticas como de fondos de inversión en estas y en las dos mayores aglomeraciones metropolitanas- parecen explicar cierta reactivación basada en la adquisición de promociones de vivienda muy devaluadas y vinculadas en bastantes casos a la cartera inmobiliaria de las entidades financieras o la SAREB.

$\mathrm{Al}$ combinar los diversos indicadores se confirma que la crisis inmobiliaria ha sido general y ha golpeado con especial intensidad a aquellas áreas con mayores ritmos de crecimiento anteriores como son las litorales y metropolitanas, aunque también son las que parecen 


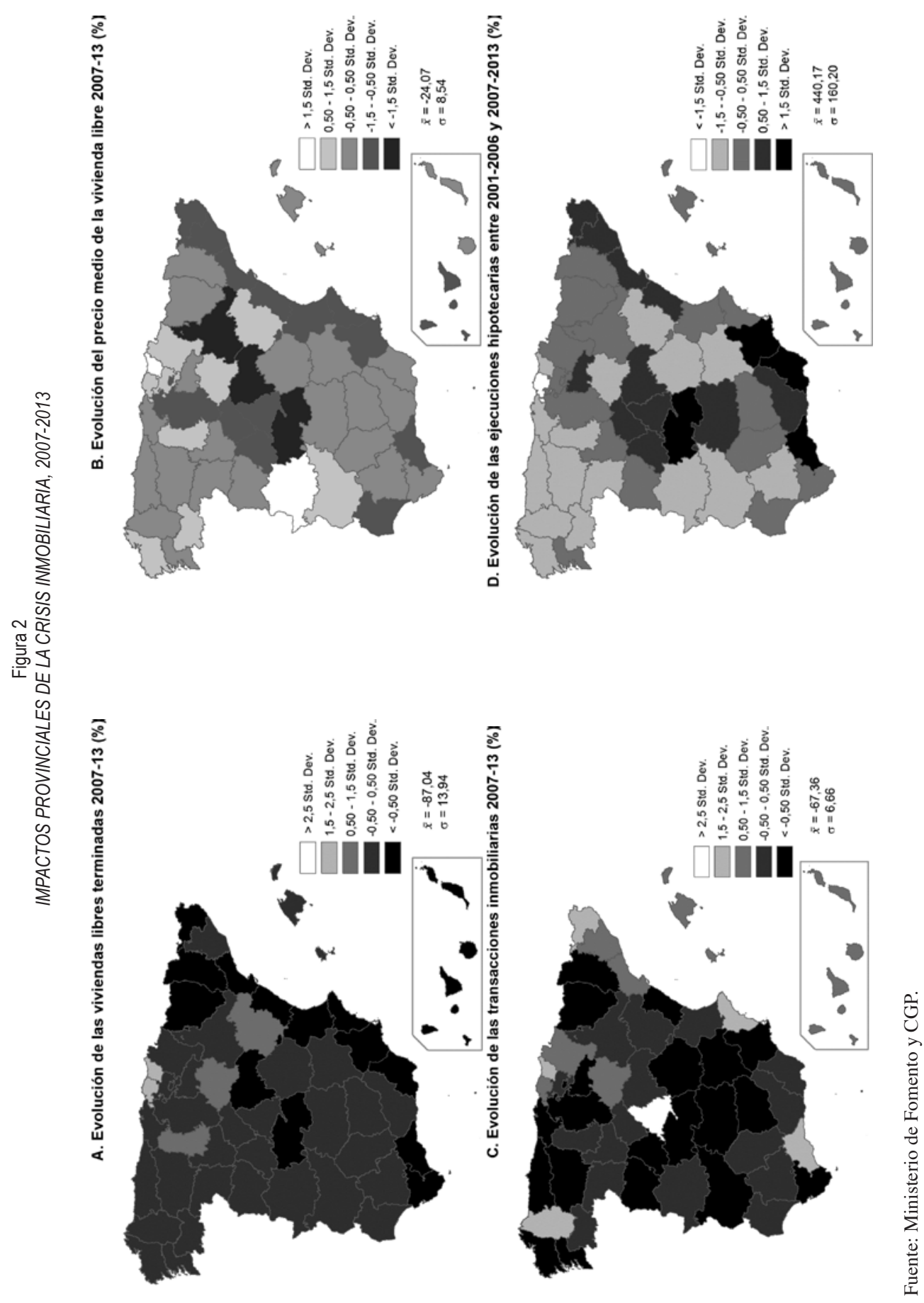


apuntar cierta reactivación reciente en la compraventa de viviendas. En el extremo opuesto, tan sólo ocho provincias han mostrado un comportamiento mejor que el promedio en esos tres indicadores, con una distribución nada casual: por una parte, las tres provincias vascas más Navarra y por otra algunas provincias interiores con baja densidad de población y un mercado inmobiliario poco dinámico (Soria, Teruel, Palencia, Cáceres), que han mantenido esa relativa moderación en las dos fases del ciclo.

A falta de un análisis estadístico más elaborado y capaz de profundizar en los mercados inmobiliarios locales, que es un objetivo ajeno a las posibilidades de este artículo, lo anterior confirma conclusiones de algún otro autor sobre el impacto diferencial provocado por el estallido de la burbuja inmobiliaria según características y trayectorias previas de cada territorio (Burriel, 2014). Esta será también la cuestión central a considerar en el caso de las ejecuciones hipotecarias, aunque a partir de una desagregación espacial no planteada hasta el momento en ninguna otra investigación y capaz de ofrecer resultados más precisos que sirvan como primera aproximación a posibles relaciones con la diferente vulnerabilidad territorial.

\section{EL MAPA DE LAS EJECUCIONES HIPOTECARIAS}

Tal como se ha señalado, las ejecuciones hipotecarias constituyen el primer paso dentro del proceso judicial que puede conducir al desahucio de un inmueble por impago de la deuda contraída y es también el que cuenta con mayor información disponible. En este sentido, los datos del Consejo General del Poder Judicial permiten diferenciar la evolución de las ingresadas o presentadas cada año de las resueltas y de aquellas otras que quedan pendientes al finalizar el año. Puede hacerse una breve comparación inicial sobre estas tres series desde el año 2001 (Figura 3), aunque el análisis territorial limitará la observación a las ingresadas para evitar reiteraciones.

Lo ocurrido en estos años pone de manifiesto la sucesión de dos fases con rasgos prácticamente opuestos y similar duración. Hasta 2006 las presentadas anualmente se situaron en torno a las quince mil, para iniciar un visible ascenso al año siguiente (25.927) que se acentuó en los sucesivos hasta llegar a un máximo de 93.610 en 2010. Desde esa fecha el incremento se ha detenido, tanto por atenuarse el impacto inicial provocado por el estallido de la burbuja inmobiliaria como por el aumento de la movilización social, traducido en una mayor presión hacia las entidades crediticias para renegociar la deuda. También en la puesta en marcha de iniciativas legislativas que, pese a tener por el momento un carácter meramente paliativo, también han contribuido a mantener la cifra en torno a las 90.000 anuales, con una leve caída en el último año.

Durante los años de crecimiento económico el número de ejecuciones hipotecarias resueltas cada año estaba próximo al de presentadas, pero el rápido crecimiento de estas últimas plantea una creciente dificultad para gestionar esos expedientes pese a la mejora registrada en ese sentido (de 17.397 en 2007 a 73.486 en 2013). La consecuencia son más de 200.000 ejecuciones hipotecarias pendientes al finalizar 2013, cifra que duplica con creces las iniciadas y multiplica por más de dos veces y media las resueltas ese año. Todo ello hace prever que el proceso de expulsión continuará mostrando cifras muy elevadas en próximos años si no se plantean respuestas más eficaces y justas que hasta el momento para frenarlo. 
Figura 3

EJECUCIONES HIPOTECARIAS INGRESADAS, RESUELTAS Y PENDIENTES, 2001-2013

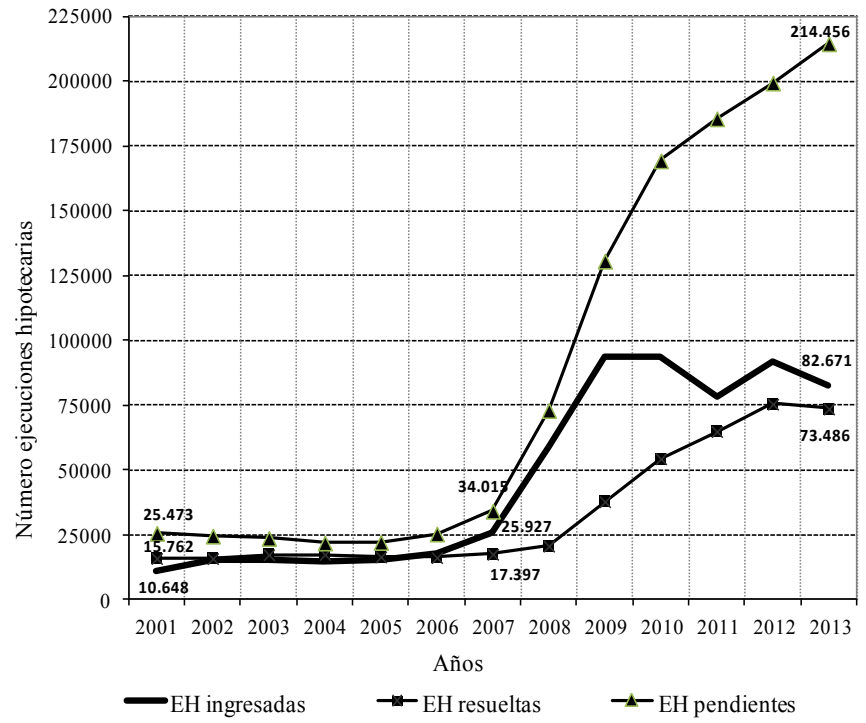

Fuente: Consejo General del Poder Judicial.

\section{VI.1. Concentración territorial y desigual intensidad según provincias: una aproximación}

No hay territorios en España que hayan quedado al margen de los negativos efectos derivados de la crisis, pero también en este caso se confirma su diferente vulnerabilidad a partir de algunas simples cifras. Sin duda las estadísticas «no nos dicen nada del miedo a perderlo todo y quedar sin nada que siente cada una de las familias que pasan por esta amarga experiencia» (Colau y Alemany, 2012: 21), pero los datos sí ayudan a precisar la magnitud del problema social y su particular gravedad en algunas áreas específicas, donde los procesos de exclusión residencial son más frecuentes.

En primer lugar, las ejecuciones hipotecarias muestran una elevada concentración territorial, pues apenas seis provincias representan casi la mitad (47,51\%) de las 497.797 iniciadas en España desde el 31 de diciembre de 2007 y hasta esa misma fecha de 2013. Por orden de importancia se sitúan Barcelona (59.030), Madrid (52.726), Alicante (38.911), Valencia (37.467), Murcia (25.037) y Málaga (23.311): Se confirma así su estrecha relación con las áreas más pobladas -estas seis provincias concentran un 41,66\% de la población residente en España- y con el crecimiento inmobiliario previo.

Esas diferencias regionales cobran su verdadero significado al comparar las ejecuciones hipotecarias presentadas en este último sexenio con las del sexenio anterior y la posición relativa de cada provincia respecto a un crecimiento medio del $440 \%$ en España. De nuevo los mayores incrementos correspondieron a provincias localizadas en ese eje (Figura 2d), con Almería $(929,30 \%)$, Málaga $(813,37 \%)$, Murcia $(701,54 \%)$ y Girona $(614,96 \%)$ en las 
primeras posiciones, acompañadas por otras situadas en la periferia externa de la aglomeración madrileña como Toledo $(730,63 \%)$, Guadalajara $(629,50 \%)$ o Ávila $(591,78 \%)$. Tasas de crecimiento equivalentes a una tercera parte o menos de esos valores máximos correspondieron, en cambio, a provincias atlánticas como Vizcaya $(198,21 \%)$, Guipúzcoa $(201,79 \%)$, Asturias (204,37\%) o Lugo (206,21\%), seguidas de cerca por otras interiores como Zamora, Palencia o León.

Si se combina esa tasa de crecimiento con la de ejecuciones presentadas en el último sexenio por cada mil habitantes se refuerza esa estricta lógica espacial en la distribución, tanto al constatarse la elevada correlación positiva entre ambas variables (coeficiente de determinación $\left.\mathrm{R}^{2}=0,6319\right)$, como al posicionar a cada provincia respecto a los correspondientes promedios (Figura 4). De este modo, las que superan ambos valores de referencia son casi todas mediterráneas, insulares o de la periferia madrileña. Por el contrario, a partir de niveles iniciales bastante bajos, el ritmo de aumento en la presentación de ejecuciones hipotecarias fue especialmente rápido en algunas provincias del Eje del Ebro y ambas Cas-

Figura 4

TIPOLOGÍA PROVINCIAL SEGÚN INTENSIDAD Y EVOLUCIÓN

DE LAS EJECUCIONES HIPOTECARIAS PRESENTADAS, 2007-2013

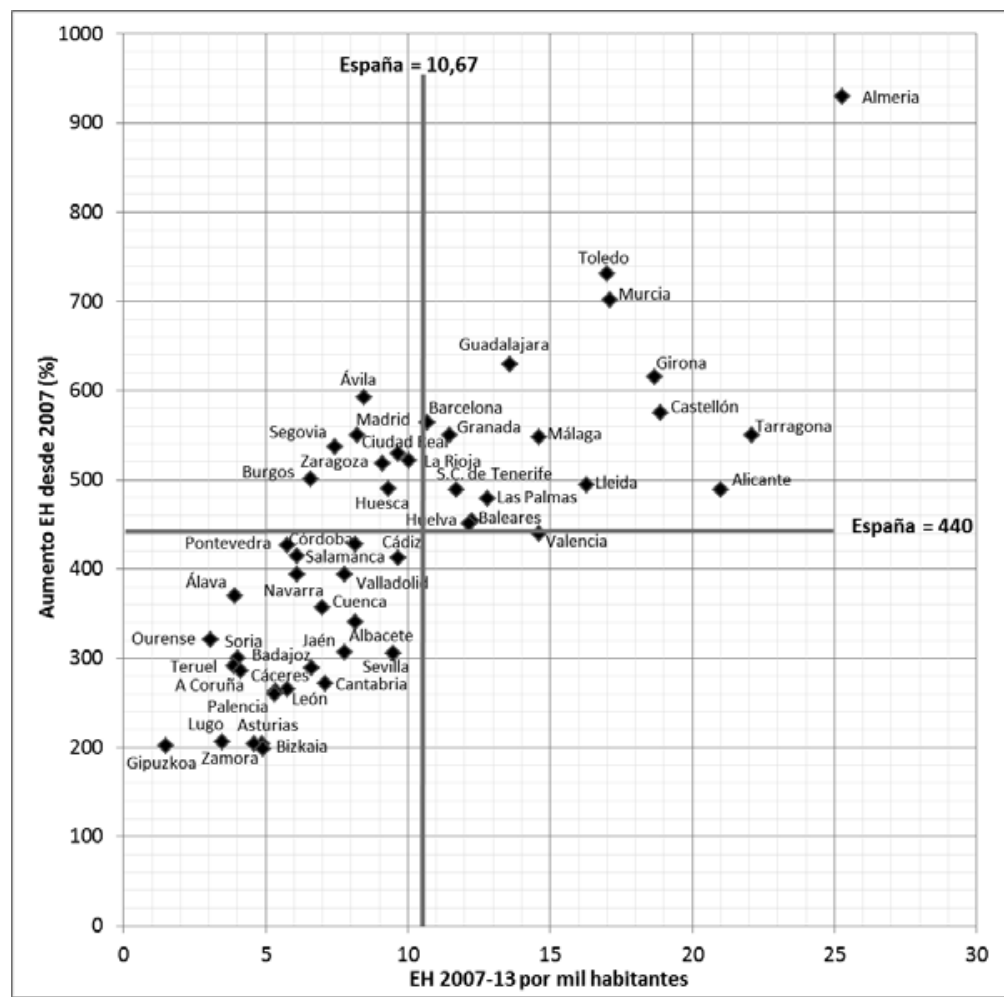

Fuente: Consejo General del Poder Judicial. 
tillas. Pero también en Madrid, lo que apunta a la importante presencia de sectores sociales especialmente vulnerables en el interior de las aglomeraciones metropolitanas y justifica el interés de aproximarse a sus contrastes internos, al menos a partir de la información actualmente disponible.

En resumen, tal como han confirmado otros estudios sobre el impacto territorial de la crisis desde la perspectiva del desempleo (Méndez, 2013a y 2013b), si hace ahora tres décadas el agotamiento del modelo de producción fordista provocó el declive de antiguas áreas industriales y mineras ubicadas, sobre todo, en el Eje Atlántico (del País Vasco a la bahía de Cádiz) frente al mejor comportamiento del Eje Mediterráneo, la actual invierte en cierto modo esa situación. Pese a la simplicidad de este tipo de esquemas dualistas, necesitados de mayor profundización, se confirma que territorios próximos y caracterizados por un modelo de crecimiento similar en las últimas décadas han recibido también impactos negativos de intensidad bastante parecida.

Así, aquellos que primaron una economía residencial basada en una urbanización acelerada y depredadora que se sustentaba en un endeudamiento masivo de empresas y familias, junto a unos servicios al consumo de baja productividad, han sido los más castigados por el brusco final del ciclo inmobiliario. Por el contrario, aquellos otros que mantuvieron su apuesta por la economía productiva y, en consecuencia, un mayor equilibrio entre la industria y los servicios, además de un mayor esfuerzo de innovación, parecen mostrar mayor capacidad de resistencia. Si los indicadores económicos y laborales muestran tan sólo una cara de una realidad poliédrica, los relativos a ejecuciones hipotecarias vienen a reforzar ese tipo de conclusiones y apuntan que los fenómenos de desposesión de los grupos más vulnerables también muestran diferencias que, con matices, reproducen esas mismas pautas territoriales.

No obstante, la provincial resulta una aproximación aún bastante grosera a la verdadera dimensión de los contrastes, que no llega a dar cuenta de la intensidad que pueden alcanzar los procesos de desalojo en ciertos ámbitos urbanos, por lo que integrar esta temática con la relativa a la segregación socio-espacial sólo será posible si se desciende a escalas más próximas. El análisis por partidos judiciales supone un paso en esa dirección y puede aportar resultados no visibles hasta el momento en la investigación realizada y publicada en España.

\section{VI.2. Ejecuciones hipotecarias por partidos judiciales y vulnerabilidad diferencial}

Abordar un análisis de las ejecuciones hipotecarias presentadas en los juzgados de primera instancia e instrucción de cada partido judicial desde el inicio de la crisis supone adentrarse en un territorio inexplorado hasta el momento en la bibliografía existente. Al incorporarse esta perspectiva dentro de un texto que pretende situar el problema de los desahucios en el contexto que supone el final de un ciclo inmobiliario, el tratamiento de esta información pretende una aproximación inicial que sirva de base a una investigación monográfica más pormenorizada y con técnicas analíticas más precisas. No obstante, esta panorámica general permite obtener ya resultados de interés al abordar los datos elaborados desde tres perspectivas complementarias (Tabla 2). 
Tabla 2

PARTIDOS JUDICIALES CON MAYOR VOLUMEN DE EJECUCIONES HIPOTECARIAS EN 2007-2013

\begin{tabular}{|l|r|l|r|l|c|}
\hline $\begin{array}{l}\text { Total EH ingresadas } \\
\text { 2007-2013 }\end{array}$ & Número & \multicolumn{1}{|c|}{$\begin{array}{c}\text { Tasa de EH } \\
2007-2013\end{array}$} & $\begin{array}{c}\text { Por mil } \\
\text { habs. }\end{array}$ & $\begin{array}{c}\text { Crecimiento de EH } \\
2007-13 / 2001-06\end{array}$ & $\%$ \\
\hline Madrid & 24.618 & Roquetas de Mar & 45,44 & Fuengirola & $1.721,90$ \\
Sevilla & 9.453 & Vera & 40,44 & Vera & $1.428,27$ \\
Barcelona & 9.378 & Torrevieja & 39,42 & Ciutadella de Menorca & $1.231,61$ \\
Valencia & 9.285 & Estepona & 38,86 & Purchena & $1.185,47$ \\
Orihuela & 8.344 & S.Bartolomé Tirajana & 35,98 & Estepona & $1.164,76$ \\
Murcia & 7.959 & Orihuela & 35,95 & Pozuelo de Alarcón & $1.075,04$ \\
Palma de Mallorca & 7.543 & San Javier & 34,41 & La Línea Concepción & $1.014,02$ \\
Alicante & 7.479 & El Ejido & 33,45 & San Javier & 992,99 \\
Zaragoza & 7.418 & Granadilla de Abona & 32,01 & Arrecife & 946,78 \\
Málaga & 7.068 & Illescas & 31,87 & Maó & 924,82 \\
Torrevieja & 5.947 & Puerto del Rosario & 31,33 & Torrox & 919,39 \\
Almería & 5.827 & Amposta & 30,99 & San Roque & 906,04 \\
Granada & 5.588 & El Vendrell & 29,33 & Archidona & 890,95 \\
Elche & 4.971 & Torrijos & 28,63 & Valverde & 889,86 \\
Castellón de la Plana & 4.831 & Gandía & 28,43 & Alcaraz & 879,05 \\
Lleida & 4.730 & Sant Feliú de Guixols & 28,20 & Sarria & 867,29 \\
Sabadell & 4.700 & Berja & 26,61 & Roquetas de Mar & 854,52 \\
Terrassa & 4.647 & Molina de Segura & 26,10 & Puerto del Rosario & 838,19 \\
Tarragona & 4.639 & Marbella & 25,89 & Villajoyosa & 829,75 \\
Gandía & 4.419 & Tortosa & 25,50 & Lalín & 800,29 \\
\hline
\end{tabular}

Fuente: Consejo General del Poder Judicial.

Si se considera el número total de ejecuciones hipotecarias ingresadas entre 2007 y 2013 , que suman un total de 523.164, su distribución territorial resulta, en principio, acorde con la que presentan tanto la población como el parque inmobiliario. El partido judicial (y municipio) de Madrid, con un total de 24.618, se sitúa a considerable distancia de Sevilla (9.453), Barcelona (9.378) o Valencia (9.285) que le siguen en importancia y entre los diez primeros también se encuentran algunas de las mayores ciudades españolas como Alicante, Murcia, Málaga o Zaragoza. El significativo grado de concentración espacial que alcanzan las ejecuciones hipotecarias se pone de manifiesto al constatar que apenas esos diez partidos judiciales entre los 431 existentes reúnen casi una de cada cinco presentadas en España $(18,84 \%)$, una proporción similar a la que representan en volumen de habitantes.

Pero en cuanto se desciende en el listado de partidos judiciales por orden de importancia se descubre que esa relación con el tamaño urbano es sólo relativa, pues entre los más castigados se sitúan muchos del litoral mediterráneo, con valores superiores a los que representa su tamaño demográfico y casos de especial relevancia como los de Orihuela o Torrevieja. Aunque el dato no se recoge en la tabla, debe mencionarse como contrapunto que en 22 partidos judiciales se presentaron durante el sexenio menos de 50 ejecuciones hipotecarias y que incluso en siete de ellos (Sahagún, Molina de Aragón, Puebla de Sanabria, A Pobra de Trives, Becerreá, A Fonsagrada y Bande) estuvieron por debajo de veinte, con una localización mayoritaria en el cuadrante noroccidental peninsular. 
Más expresiva de la gravedad que alcanzan los procesos de desahucio resulta su intensidad, aquí estimada respecto al número de residentes al no existir datos anualizados sobre el stock de vivienda a esta escala espacial. Tras calcular el valor medio de la población en cada partido judicial para el periodo 2007-13 a partir de las cifras anuales del Padrón Municipal, pudo definirse el volumen de ejecuciones hipotecarias por cada mil habitantes (Tabla 2) y cartografiar su distribución (Figura 5). Como era previsible, ese parámetro alcanza sus niveles más elevados en las áreas turísticas litorales donde la construcción masiva de viviendas destinadas a segunda residencia para unos grupos sociales que contaban en su momento con ingresos medios y un empleo que permitía afrontar el pago de la deuda contraída, se salda ahora con un fuerte incremento de esa tasa. Las 45,44 ejecuciones hipotecarias por mil habitantes de Roquetas de Mar (Almería) son el valor más elevado, que cuadruplica con creces el promedio español. Más expresivo aún resulta que 15 de los 20 partidos con mayores densidades se localicen en el litoral mediterráneo y otros tres en Canarias.

Figura 5

EJECUCIONES HIPOTECARIAS INICIADAS EN 2007-13 POR PARTIDOS JUDICIALES (POR MIL HAB.)

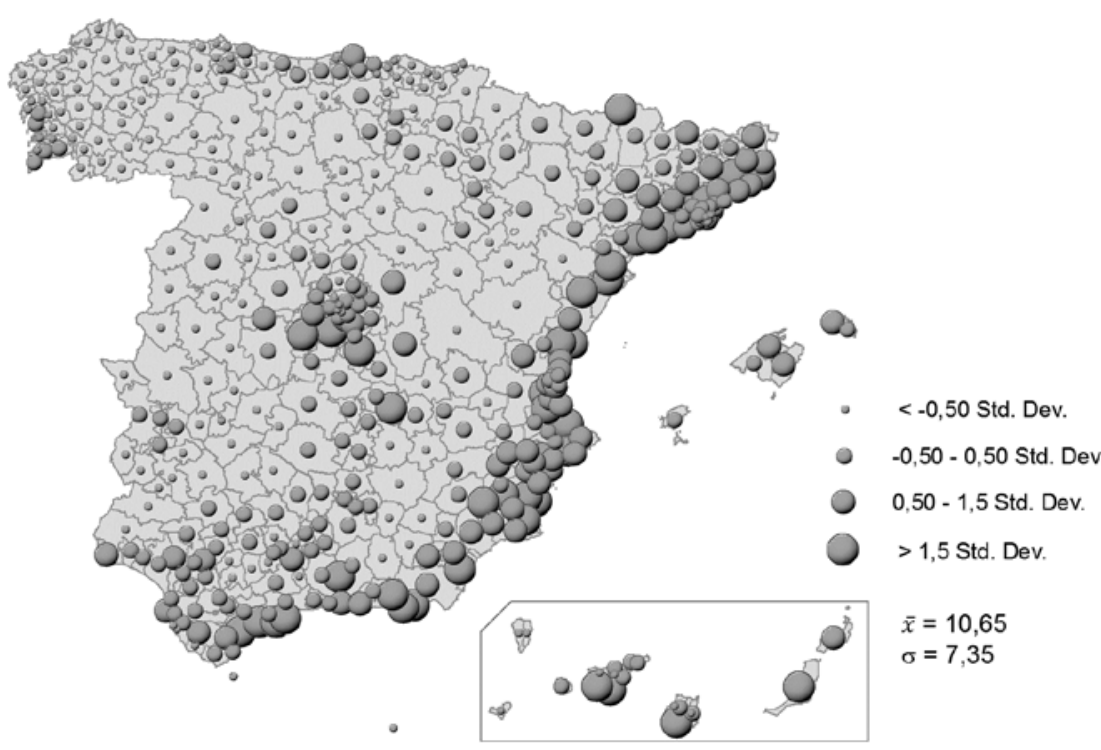

Fuente: Consejo General del Poder Judicial. Elaboración propia

Pero no deben ignorarse las altas tasas que también se registran en la periferia metropolitana de Madrid y su entorno periurbano, especialmente en su sector meridional (Illescas, Torrijos, Parla, Valdemoro...), donde se instaló una población joven, a menudo con empleos inestables, en urbanizaciones de menor calidad y precio que las de áreas centrales o noroccidentales de la aglomeración, atrapada ahora por el deterioro de sus condiciones laborales. Algunos valores también elevados en áreas interiores de Castilla-La Mancha, Andalucía 
o el valle del Ebro, además del Pirineo, plantean la necesidad de profundizar en el futuro este panorama inicial. De nuevo en el extremo opuesto, un total de 19 partidos judiciales no alcanzan siquiera la cuarta parte de la densidad media en España, con tres cuartas partes de los casos en las provincias atlánticas.

El inicio del proceso judicial que puede conducir al desahucio guarda, sin duda, relación directa con las condiciones sociales de los afectados y su vulnerabilidad personal, pero los evidentes contrastes en su distribución geográfica confirman la existencia de una vulnerabilidad territorial también muy selectiva, asociada sobre todo a su diverso grado de exposición al riesgo. Eso se confirma al calcular y cartografiar el crecimiento de las ejecuciones hipotecarias desde el inicio de la crisis y hasta la actualidad (2007-13) respecto a las presentadas en el sexenio anterior (2001-06), ambas en relación con el respectivo promedio de población de cada periodo (Tabla 2 y Figura 6).

En un total de siete partidos judiciales el incremento superó el $1000 \%$ frente a otros siete donde no se alcanzó el 100\%, con valores extremos en Fuengirola $(1721,90 \%)$, Vera $(1428,27 \%)$, Ciutadella $(1231,61 \%)$, Purchena $(1185,47 \%)$ y Estepona $(1164,76 \%)$. De nuevo el Eje Mediterráneo muestra un indudable protagonismo por el mayor número de casos con crecimientos muy superiores al promedio español, pero la unidad territorial aquí utilizada permite precisar los ámbitos donde el problema se agudiza. Dentro de ese litoral, por ejemplo, las máximas tasas se alcanzan en el Campo de Gibraltar (Algeciras, San Roque), Costa del Sol (Fuengirola, Estepona) y otras áreas de Málaga (Antequera, Torrox, Vélez-Málaga), el levante almeriense y valle del Almanzora (Vera, Huércal Overa, Purchena), el mar Menor y Campo de Cartagena, la Marina de Alicante (Villajoyosa), la Ribera Alta y Horta Sur valenciana (Alzira, Carlet, Picassent), el delta del Ebro (Amposta) y el Baix Maestrat (Vinarós, Benicarló), o la isla de Menorca. Fuera de él, junto a algunas islas canarias (Lanzarote, Fuerteventura, El Hierro, sur de Tenerife) hay que destacar el crecimiento registrado en el Pirineo aragonés y catalán (Jaca, Boltaña, La Seu d’Urgell, Vielha, Tremp), así como en algunos núcleos urbanos gallegos (Sarria, Lalín, O Porriño, Vilagarcía de Arousa, Padrón). Pero aún más visible resulta la formación de una corona externa a la región metropolitana de Madrid, que se prolonga en dirección al sur (Sagra, Mesa de Ocaña) y tiene continuidad en algunas áreas de su interior, así como en la propia capital, algo que también ocurre en la aglomeración de Barcelona (Vallés Oriental y Occidental, Bages).

Una última etapa en este recorrido pretendió establecer algunas regularidades esenciales en la distribución territorial que presentan los valores de densidad y evolución registrada por las ejecuciones hipotecarias desde el inicio de la crisis, sin entrar por el momento en análisis estadísticos multivariantes más complejos. Para ello se definió una tipología de partidos judiciales en función de su posición relativa respecto al promedio de esos dos indicadores, lo que permitió establecer cuatro grupos que muestran una regionalización bien definida (Figura 7), así como una categorización territorial según la localización de los partidos judiciales (Tabla 3).

La situación más negativa es, sin duda, la que presentan aquellos donde a la elevada densidad de ejecuciones hipotecarias se añade su espectacular aumento desde 2007 (Tipo D). Tal como se ha repetido de forma insistente, forman un cinturón casi continuo que bordea el litoral mediterráneo e incorpora la práctica totalidad de provincias como Murcia, Almería 
Figura 6

EVOLUCIÓN DE LAS EJECUCIONES HIPOTECARIAS INICIADAS EN 2007-13

RESPECTO A 2001-06 POR PARTIDOS JUDICIALES (\%)

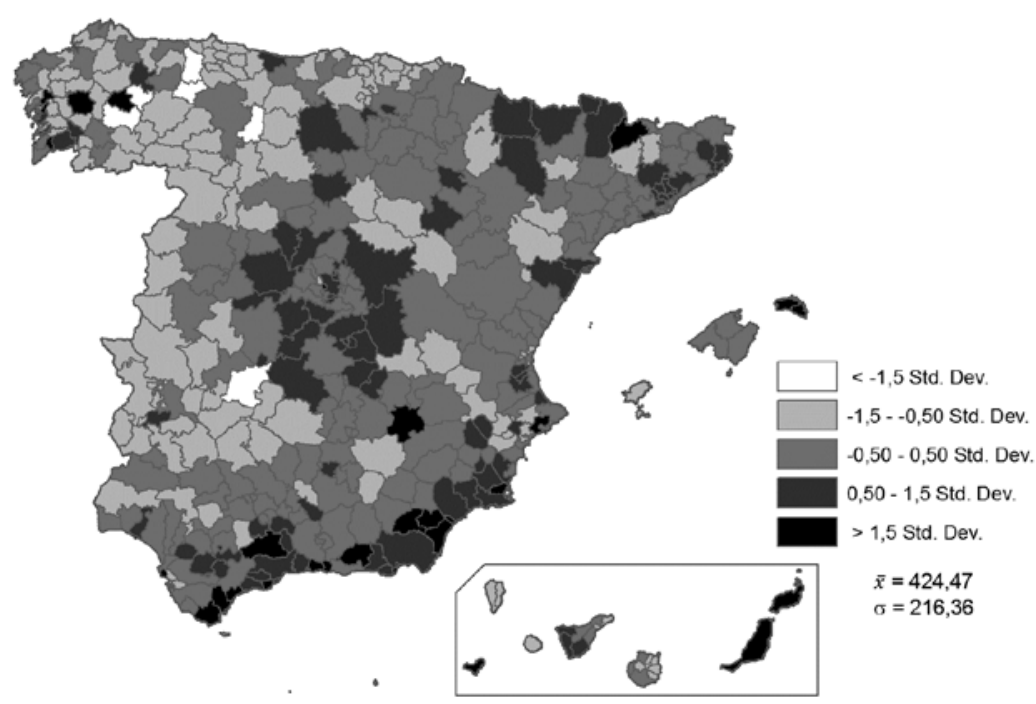

Fuente: Consejo General del Poder Judicial. Elaboración propia.

Figura 7

TIPOLOGÍA DE PARTIDOS JUDICIALES SEGÚN DENSIDAD Y EVOLUCIÓN

DE LAS EJECUCIONES HIPOTECARIAS DURANTE LA CRISIS

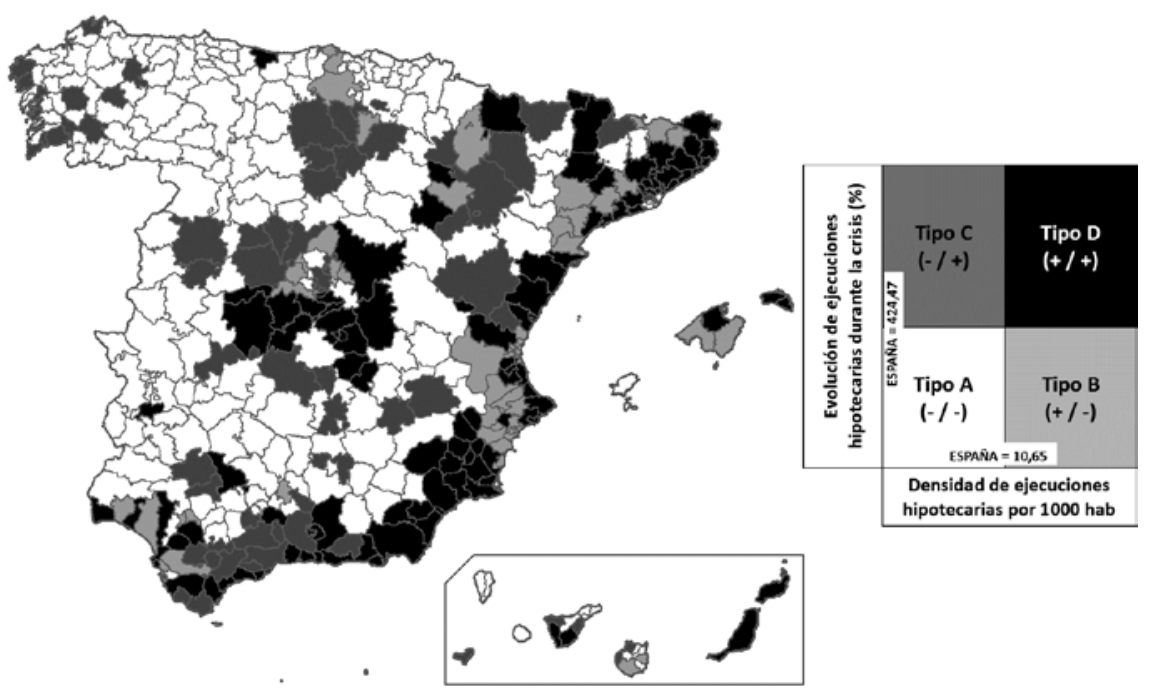

Fuente: Consejo General del Poder Judicial y elaboración propia. 
o Castellón. Su relación prioritaria con la construcción residencial vinculada al turismo y la segunda vivienda se repite en las comarcas pirenaicas aragonesas y catalanas, así como en algunas islas, aunque el volumen total en estos casos sea bastante inferior. Muy distinto es, en cambio, el origen de la elevada densidad y crecimiento que han registrado las ejecuciones hipotecarias en determinados sectores de las periferias metropolitanas de Madrid (Sur y Este Metropolitanos), Barcelona (Vallés Occidental y Oriental, Bages), Sevilla (Aljarafe, Bajo Guadalquivir) o Valencia (l'Horta, Ribera Baixa), que registraron un proceso de urbanización más intenso y/o donde residen los grupos sociales más vulnerables. Junto a estas áreas donde partidos judiciales contiguos muestran comportamientos similares que responden a lógicas comunes, también se detectan valores muy elevados en algunos núcleos dispersos cuya justificación remite, sobre todo, a sus estrategias inmobiliarias en el pasado reciente, desde Llanes o Ayamonte en la costa, a Granada, Santa Fe, Calatayud, Tarazona, Almendralejo, Lucena o Alcoy en el interior.

Situación próxima es la de aquellos partidos donde el fuerte crecimiento reciente no supone que su densidad actual supere el promedio por partir de niveles muy bajos (Tipo C). En bastantes casos constituyen una aureola externa al tipo anterior, pero también integra a determinadas capitales provinciales interiores que experimentaron un fuerte crecimiento de la construcción residencial (Zaragoza, Burgos, Logroño, Salamanca, Ávila, Segovia, Ciudad Real, Orense), así como a la ciudad de Madrid y núcleos de su primera corona metropolitana. Menos numerosos y siempre contiguos a los anteriores son los partidos que mantienen una densidad superior al promedio, aunque su tasa de crecimiento resultó más moderada (Tipo B), especialmente numerosos en las comarcas interiores catalanas y valencianas, litoral atlántico andaluz y cántabro, o sectores menos urbanizados de la región madrileña. En el resto del territorio el problema de las ejecuciones hipotecarias no está ausente, pero su importancia es bastante menor (Tipo A). Aquí se sitúa la mayoría de áreas rurales y pequeñas ciudades de las regiones interiores, pero hay Comunidades Autónomas donde todos o casi todos sus partidos judiciales se integran en este tipo, lo que obliga a considerar las estrategias de desarrollo aplicadas en cada caso y la pervivencia de estructuras económicas más equilibradas, con predominio de los servicios y de una industria renovada frente al monocultivo turístico-residencial como posible factor de protección. El País Vasco, Navarra, Asturias, Extremadura y, hasta cierto punto, Castilla y León son las más representativas.

Para finalizar el análisis, se llevó a cabo una categorización territorial de los partidos judiciales según su localización. Como estas unidades espaciales no permiten la delimitación rigurosa de unidades territoriales como, por ejemplo, las de carácter metropolitano, los partidos se agruparon por provincias y en cinco conjuntos diferenciados. Se identificaron como metropolitanas las siete que cuentan con las siete grandes áreas urbanas que superaban los 750.000 habitantes en 2012 según el Atlas Estadístico de las Áreas Urbanas de España publicado por el Ministerio de Fomento, para diferenciarlas de otras provincias litorales mediterráneas o atlánticas, de otras provincias interiores y de las del archipiélago canario, resumiendo los resultados obtenidos en la Tabla 3. Se confirma así que las provincias metropolitanas ya concentraban el 39,49\% de las ejecuciones hipotecarias en el primer sexenio del siglo, pero aumentaron esa proporción al 40,87\% de las registradas entre 2007 y 2013 , con una tasa de crecimiento del $513,01 \%$, pero que ese aumento fue aún mayor en las otras provincias litorales mediterráneas, donde se alcanzó un 580,75\% por las 
razones ya señaladas. Situación bien distinta es la de los partidos judiciales localizados en las provincias atlánticas (salvo Vizcaya), donde la tasa media de incremento se situó en un $325,80 \%$, así como en las provincias interiores $(442,96 \%)$, quedando los partidos canarios en situación intermedia $(483,53 \%)$.

Tabla 3

EVOLUCIÓN DE LAS EJECUCIONES HIPOTECARIAS POR PARTIDOS JUDICIALES SEGÚN ÁMBITOS TERRITORIALES, 2001-2013

\begin{tabular}{|l|r|r|r|r|r|}
\hline Localización de los Partidos Judiciales & $\begin{array}{c}\text { EH 2001- } \\
\text { 2006 (A) }\end{array}$ & \% Total & $\begin{array}{c}\text { EH 2007- } \\
\text { 2013 (B) }\end{array}$ & \% Total & $\begin{array}{c}\text { Crecimiento } \\
\text { B/A (\%) }\end{array}$ \\
\hline Provincias metropolitanas * & 34.915 & 39,49 & 214.031 & 40,87 & 513,01 \\
Otras prov. litorales mediterráneas ** & 21.274 & 24,06 & 144.822 & 27,65 & 580,75 \\
Otras prov. litorales atlánticas *** & 10.209 & 11,55 & 43.470 & 8,30 & 325,80 \\
Otras provincias interiores **** & 17.383 & 19,66 & 94.382 & 18,02 & 442,96 \\
Provincias canarias & 4.633 & 5,24 & 27.035 & 5,16 & 483,53 \\
\hline Total & 88.414 & 100 & 523.740 & 100 & 492,37 \\
\hline
\end{tabular}

Fuente: Consejo General del Poder Judicial y elaboración propia.

* Madrid, Barcelona, Valencia, Sevilla, Málaga, Vizcaya, Zaragoza

** Girona, Tarragona, Castellón, Alicante, Murcia, Almería, Baleares

*** Guipúzcoa, Cantabria, Asturias, Lugo, A Coruña, Pontevedra, Huelva, Cádiz

***** Restantes provincias salvo las dos canarias

\section{CONCLUSIONES}

Los desahucios hipotecarios son una de las más importantes y trágicas manifestaciones sociales del impacto de la crisis inmobiliaria iniciada en 2007. El aumento de la morosidad derivado del elevado desempleo, la creciente precarización del trabajo o las reducciones salariales ha elevado el número de ejecuciones hipotecarias presentadas en los juzgados de primera instancia e instrucción desde poco más de diez mil al iniciarse el siglo hasta cifras en torno a las noventa mil anuales desde 2009, lo que supone superar el medio millón en los seis últimos años. La aproximación geográfica aporta el enfoque necesario para identificar los ámbitos territoriales más vulnerables a este fenómeno, pero no ha sido aun suficientemente tratada a pesar de la urgencia de respuestas políticas y legislativas para corregir este problema. Este trabajo centra la atención en la distribución espacial de los principales indicadores que caracterizan la caída del mercado de la vivienda y, más concretamente, en unas ejecuciones hipotecarias que se ceban sobre los colectivos y territorios más frágiles, materializando nuevas formas de exclusión social y residencial.

El continuo incremento anual de desahucios es consecuencia de una carrera para consolidar una sociedad de propietarios donde la vivienda perdió en buena medida su función social frente a su consideración como inversión financiera con resultados a corto plazo. La espiral especulativa fue facilitada por una burbuja crediticia ajena a las buenas prácticas bancarias y centrada en captar nuevos clientes atraídos por el efecto riqueza que suponía la revalorización de los activos inmobiliarios. 
Entre las consecuencias más evidentes de la quiebra de esta espiral inmobiliaria no sólo destaca el paisaje desolador derivado de un gran stock de viviendas vacías, suelo urbanizado y abandonado o ciudades desordenadas, junto a su efecto sobre la caída de ingresos para las haciendas locales y el incremento de la deuda pública, sino también su impacto en el empleo y en las rentas de las familias, entre cuyas obligaciones económicas se incluye la devolución de los créditos hipotecarios contraídos en los años previos para adquirir sus viviendas. En este escenario, aquellas especialmente vulnerables, atrapadas en el impago de su deuda se han visto afectadas por los procedimientos judiciales de desahucio, pero su número en rápido aumento ha convertido estas situaciones particulares en problemas sociales y manifestaciones de procesos de desarrollo desigual con una raíz explicativa profundamente geográfica. Podemos hablar por tanto de la definición de áreas-problema donde la acumulación de actos judiciales de desahucio alimenta un paisaje urbano ya desolado con las tensiones y tragedias de los que se ven forzados a abandonar sus casas.

La identificación y clasificación de las áreas más o menos afectadas por las ejecuciones hipotecarias es posible mediante un análisis espacial de las estadísticas disponibles a escala provincial y, sobre todo, de los partidos judiciales donde los juzgados de primera instancia llevan a cabo estos procedimientos. Dos indicadores sobre la dinámica de las ejecuciones hipotecarias nos revelan el grado de exposición diferencial del territorio frente a la crisis: la densidad de desahucios por mil habitantes y el crecimiento observado entre el periodo estudiado (2007-2013) y los años anteriores (2001-2006). La relación entre ambos conduce a una clasificación de los partidos judiciales en cuatro tipos, desde aquellos donde el problema de los desahucios tiene una importancia modesta hasta la situación más negativa que representan las áreas con una elevada densidad y un crecimiento acelerado en los últimos años. La cartografía resultante permite así completar otros análisis recientes sobre el impacto diferencial de la crisis inmobiliaria en España confirmando algunas tendencias territoriales consistentes.

Por un lado están las áreas turísticas del litoral mediterráneo, así como algunas islas y valles pirenaicos donde la construcción masiva de segundas residencias se salda ahora con densidades de ejecuciones hipotecarias que llegan a cuadruplicar el promedio español y tasas de crecimiento en apenas seis años que superan tasas del $800 \%$. Por otro, las periferias externas de las principales aglomeraciones metropolitanas, exponente destacado del modelo de urbanización de baja densidad, con una especial intensidad en aquellos sectores donde residen los grupos sociales de menores ingresos y más afectados ahora por el desempleo y la precariedad laboral, que se enfrentan a crecientes dificultades para el pago de su deuda hipotecaria, aunque sin olvidar otras áreas interiores, asiento tradicional de clases medias progresivamente amenazadas por las políticas de austeridad. Finalmente, el mapa muestra una serie de puntos negros dispersos por el territorio, donde la gravedad de la actual situación se deriva en buena medida de los excesos cometidos en el pasado reciente por las estrategias locales de promoción inmobiliaria.

En resumen, el enfoque territorial aquí planteado sobre las ejecuciones hipotecarias nos aproxima a una realidad principalmente urbana, consecuente con la distribución desigual de la riqueza y la segregación espacial de los grupos sociales más vulnerables ante los procesos de acumulación, que ahora se enfrentan a la desposesión de uno de los derechos fundamentales como es el de la vivienda. Profundizar en estos paisajes después de la batalla cuya huella tardará en borrarse en bastantes áreas de nuestro territorio supone, por tanto, un reto de futuro para los estudios geográficos y este texto ha pretendido aportar una primera panorámica general. 


\section{BIBLIOGRAFÍA}

AGÜERO, A. (2014): Estadística sobre procesos de ejecución hipotecaria del Banco de España. Ciudad Real, Centro de Estudios del Consumo.

ALGUACIL, J.; CAMACHO, J. y HERNÁNDEZ AJA, A. (2014): «La vulnerabilidad urbana en España. Identificación y evolución de los barrios vulnerables». EMPIRIA. Revista de Metodología de Ciencias Sociales, ${ }^{\circ}$ 27, 73-94.

ALGUACIL DENCHE, A. et al. (2013): La vivienda en España en el siglo XXI. Diagnóstico del modelo residencial y propuestas para otra política de vivienda. Madrid, Cáritas y Fundación FOESSA.

ARREDONDO, R. Y PALMA, M.O. (2013): «Aproximación a la realidad de los desahucios. Perfil y características de las familias en proceso de desahucios en la ciudad de Málaga». Alternativas, $\mathrm{n}^{\circ}$ 20, 113-140.

AXEL-LUTE, M. (2009): Communities at risk. How the foreclosure crisis is damaging urban areas and what is being done about it. Washington, D.C., Living Cities.

BANCO DE ESPAÑA (2013): Nota informativa sobre la presentación de una nueva estadística de procesos de ejecución hipotecaria sobre viviendas. Madrid, Banco de España.

BEEN, V. y GOULD, I. (2012): Challenges Facing Housing Markets in the Next Decade. Developing a Policy-Relevant Research Agenda. Nueva York, Furman Center for Real State \& Urban Policy y The Institute for Affordable Housing Policy.

BELLAMY, FOSTER J. y MAGDOFF, F. (2009): «Implosión financiera y estancamiento: el regreso a la economía real» en La debacle de Wall Street y la crisis del capitalismo global, 2007-2009 (Beitel, K. et al.). Barcelona, Hacer Editorial, 37-69.

BURRIEL, E. (2008): «La década prodigiosa del urbanismo español (1997-2006)». Scripta Nova, vol. XII, no 270(64), 1 de agosto de 2008. Universidad de Barcelona. Disponible en http://www.ub.es/geocrit/sn/sn-270/sn-270/sn-270-64.htm>

BURRIEL, E. (2011): «Subversion of land-use plans and the housing bubble in Spain». Urban Research \& Practice, vol. 4, n 3, 232-249.

BURRIEL, E. (2014): «El estallido de la burbuja inmobiliaria y sus efectos en el territorio» en Geografía de la crisis económica en España (Albertos, J.M. y Sánchez, J.L., coords.). Valencia, Publicaciones Universidad de Valencia, 101-140.

CAPEL, H. (2013): La morfología de las ciudades. III. Agentes urbanos y mercado inmobiliario. Barcelona, Ediciones del Serbal.

COLAU, A. (2012): «La vivienda en España: un derecho por conquistar» en Ciudades, una ecuación imposible (Belil, M.; Borja, J., y Corti, M., eds.). Barcelona, Icaria, 113-130.

COLAU, A. y ALEMANY, A. (2012): Vidas hipotecadas. De la burbuja inmobiliaria al derecho a la vivienda. Barcelona, Cuadrilátero de Libros.

COLAU, A. y ALEMANY, A. (2013): 2007-2012: retrospectiva sobre desahucios y ejecuciones hipotecarias en España, estadísticas oficiales e indicadores. Barcelona, Plataforma de Afectados por la Hipoteca.

CONSEJO GENERAL DEL PODER JUDICIAL (2013): «Una aproximación a la conciliación de los datos sobre ejecuciones hipotecarias y desahucios». Datos de Justicia. Boletín de Información Estadística, $\mathrm{n}^{\circ}$ 35, 1-9. 
DAHER, A. (2013): «El sector inmobiliario y las crisis económicas». EURE. Revista de Estudios Urbanos y Regionales, vol. 39, $\mathrm{n}^{\circ}$ 118, 47-76.

DAY, D.; GRINDSTED, A.; PIQUARD, B. y ZAMMIT, D. eds. (2009): Cities and Crises. Bilbao, University of Deusto.

DE MATTOS, C. (2007): «Globalización, negocios inmobiliarios y transformación urbana». Nueva Sociedad, $\mathrm{n}^{\circ}$ 212, 82-96.

ETXEZARRETA, A.; CANO, G.; HOEKSTRA, J. y DOL, K. (2013): «Análisis multiescalar de la burbuja inmobiliaria y los desahucios: la Comunidad Autónoma de Euskadi en el contexto estatal y europeo». Revista de Estudios Regionales, $\mathrm{n}^{\circ}$ 98, 51-76.

ETXEZARRETA, A.; HOEKSTRA, J.; DOL, K. y CANO, G. (2012): «De la burbuja inmobiliaria a las ejecuciones hipotecarias». Ciudad y Territorio Estudios Territoriales, vol. XLIV, $n^{\circ} 174,597-613$.

FERNÁNDEZ DURÁN, R. (2006): El tsunami urbanizador español y mundial. Madrid, Ecologistas en Acción. Disponible en http://www.nodo50.org/ramonfd/tsunami urbanizador.pdf].

FERNÁNDEZ TABALES, A. y CRUZ, E. (2013): «Análisis territorial del crecimiento y la crisis del sector de la construcción en España y la Comunidad Autónoma de Andalucía». EURE. Revista de Estudios Urbanos y Regionales, vol. 39, nº 116, 5-37.

GARCÍA, M. (2010): «The Breakdown of the Spanish urban model: Social and territorial effects of the Global Crisis». International Journal of Urban and Regional Research, vol. $34, \mathrm{n}^{\circ} 4,967-980$.

GARCÍA MONTALVO, J. y MÁS, M. (2000): La vivienda y el sector de la construcción en España. Valencia, Instituto Valenciano de Investigaciones Económicas.

HADJIMICHALIS, K. (2011): «Uneven geographical development and socio-spatial justice and solidarity: European regions after 2009 financial crisis». European Urban and Regional Studies, vol. 18, $\mathrm{n}^{\circ} 3,54-274$.

HARDING, J.P.; ROSENBLATT, E. y YAO, V.W. (2008): «The contagion effect of foreclosed properties». Journal of Urban Economics, vol. 66, n 3, 164-178.

HARVEY, D. (2004): El nuevo imperialismo. Madrid, Akal.

HARVEY, D. (2007): Espacios del capital. Hacia una geografía crítica. Madrid, Akal.

HERCE, M. (2013): El negocio del territorio. Evolución y perspectivas de la ciudad moderna. Madrid, Alianza Editorial.

HERNÁNDEZ AJA, A. (2007): «Áreas vulnerables en el centro de Madrid». CI[UR] Cuadernos de Investigación Urbanística, $\mathrm{n}^{\circ}$ 53, 1-102.

IMMERGLUCK, D. y SMITH, G. (2006): «The external costs of foreclosure: the impact of single-family mortgage foreclosures on property values». Housing Policy Debate, vol. 17, $\mathrm{n}^{\mathrm{o}} 1,57-79$.

KAPLAN, D.H. y SOMMERS, G.G. (2009): «An Analysis of the Relationships between Housing Foreclosures, Lending Practices and Neighborhood Ecology: Evidence from a Distressed County». The Professional Geographer, vol. 61, n 1, 101-120.

KINGSLEY, G.T.; SMITH, R. y PRICE, D. (2009): The impacts of foreclosures on families and communities. Washington, D.C., The Urban Institute.

KRUGMAN, P. (2009): El retorno de la economía de la depresión y la crisis actual. Barcelona, Crítica. 
LÓPEZ, I. y RODRÍGUEZ, E. (2010): Fin de ciclo. Financiarización, territorio y sociedad de propietarios en la onda larga del capitalismo hispano (1959-2010). Madrid, Traficantes de Sueños.

LÓPEZ, I. y RODRÍGUEZ, E. (2013): «Competitividad territorial y circuito secundario de acumulación. El paroxismo de un caso: el ciclo español de 1995-2007» en Paisajes devastados. Después del ciclo inmobiliario: impactos regionales y urbanos de la crisis (Observatorio Metropolitano de Madrid, Ed). Madrid, Traficantes de Sueños, 25-75.

MÉNDEZ, R. (2013a): Las escalas de la crisis. Ciudades y desempleo en España. Madrid, Fundación $1^{\circ}$ de Mayo, Colección Estudios, nº 60, 1-146.

MÉNDEZ, R. (2013b): «Crisis económica, vulnerabilidad urbana y desempleo en España». Ciudad y Territorio Estudios Territoriales, vol. XLV, nº 178, 649-667.

MÉNDEZ, R. y PRADA, J. (2014): «Crisis, desempleo y vulnerabilidad en Madrid». Scripta Nova. Revista Electrónica de Geografía y Ciencias Sociales, vol. XVIII, nº 474, 20 de abril de 2014. Disponible en http://www.ub.edu/geocrit/sn/sn-474.htm.

NACIONES UNIDAS (2003): Informe sobre la situación social del mundo 2003. Vulnerabilidad social: fuentes y desafíos. Nueva York, ONU, Departamento de Asuntos Económicos y Sociales.

NAREDO, J.M. (2009): «La cara oculta de la crisis. El fin del boom inmobiliario y sus consecuencias». Revista de Economía Crítica, $\mathrm{n}^{\circ}$ 7, 313-340.

NAREDO, J.M. (2010): «El modelo inmobiliario español y sus consecuencias». Boletín $C F+S, 44,13-27$. Disponible en http://habitat.aq.upm.es/boletin/n44/ajnar.html.

RANZI, C.; BRANDSEN, T. y SABATINELLI, S. (2014): Social Vulnerability in European Cities. The Role of Local Welfare in Times of Crisis. Londres, Palgrave Macmillan.

REGISTRADORES DE ESPAÑA (2013): Panorama registral. Impagos hipotecarios de vivienda 2012. Madrid, Colegio de Registradores de la Propiedad, Bienes Muebles y Mercantiles de España.

RODRÍGUEZ LÓPEZ, J. (2009): «La crisis de los mercados inmobiliario e hipotecario. Factores explicativos». Papeles de Economía Española, n ${ }^{\circ}$ 122, 236-253.

ROMERO, J. (2010): «Construcción residencial y gobierno del territorio en España. De la burbuja especulativa a la recesión. Causas y consecuencias». Cuadernos Geográficos, $\mathrm{n}^{\circ}$ 47, 17-46.

ROMERO, J.; JIMÉNEZ, F. y VILLORIA, M. (2012): «(Un)sustainable territories: causes of the speculative bubble in Spain (1996-2010) and its territorial, environmental and sociopolitical consequences». Environment and Planning C: Government and Policy, vol. 30, $\mathrm{n}^{\circ} 3,467-486$.

SÁNCHEZ MARTÍNEZ, M. (2008): «Boom inmobiliario y financiero: el final del ciclo». Cuadernos de Información Económica, $\mathrm{n}^{\circ} 205,101-111$.

SEELIGER, L. y TUROK, I. (2013): «Towards sustainable cities: extending resilience with insights from vulnerability and transition theory». Sustainability, $\mathrm{n}^{\circ} 5,2108-2128$. Disponible en http://www.mdpi.com/2071-1050/5/5/2108

TRABADA, E. (2012): «El problema de la vivienda en una sociedad que se dualiza». Documentación Social, $\mathrm{n}^{\circ} 165,165-188$. 
VALENZUELA, M. (2013): «La vivienda tras la burbuja: grandes retos para un futuro incierto» en Informe España 2013. Una interpretación de su realidad social. Madrid, Fundación Encuentro, 291-425.

VALIÑO, V. (coord.) (2013): Emergencia habitacional en el Estado español. La crisis de las ejecuciones hipotecarias y los desalojos desde una perspectiva de derechos humanos. Barcelona, Observatorio DESC y Plataforma de Afectados por la Hipoteca.

VINUESA, J. (2013): El festín de la vivienda. Auge y caída del negocio inmobiliario en España. Madrid, Díaz \& Pons. 
